\title{
The Structural Relationship between Adolescents' Participation in Sport, Socialization Agents, and Adolescents' Life Satisfaction
}

\section{IJCRR}

Section: Healthcare

Sci. Journal Impact

Factor: 6.1 (2018)

ICV: 90.90 (2018)

Copyright@IJCRR

\section{Seungman Lee ${ }^{1}$, Jihwan Song ${ }^{2}$, Song Hohyun ${ }^{3}$}

\begin{abstract}
'Kyunghee University, Department of Physical Education, Republic of Korea; ']eonju National University of Education, Department of
Physical Education, Republic of Korea; 3]eonjuHosung Middle School, Department of Physical Education, Republic of Korea.
\end{abstract}

\section{ABSTRACT}

This study aimed to verify the relationship between youth sport participation, socialization agents, and life satisfaction.

Aim and Scope: It is conducted on a pilot study of 181 adolescents residing in Seoul in December 2019 and the main study of 539 adolescents residing in Seoul in February 2020. Data acquired from both the pilot and main study were analyzed using frequency analysis, reliability analysis, validity analysis, descriptive statistics analysis, and path analysis.

Method: These analyses yielded the following results. First, socialization agents were found to influence sport participation positively. Second, sports participation motivation was found to influence sport participation positively. Third, sports participation engagement was found to influence sport participation positively.

Conclusion: Based on these findings, this study discussed the importance of recognizing socialization agents' importance in driving adolescents' motivation to participate in sports and the need to provide adolescents with a variety of sport participation opportunities to raise their life satisfaction.

Key Words: Adolescents, Sports Participation Motivation, Socialization Agents, Life Satisfaction, Structural Equation Modeling

\section{INTRODUCTION}

Adolescents' quality of life has been researched extensively. Adolescence is the developmental stage connecting childhood and adulthood; therefore, adolescence is seen as a bright, optimistic time in one's life, and adolescents are often challenged to assert, challenge, and fulfil their potential. However, adolescents in the Republic of Korea have reported the lowest levels of happiness among adolescents in OECD member countries. Education experts have asserted that university entrance exams and the widespread social emphasis on academic achievement, which equates selfworth and academic achievement, are the main reasons for this low level of adolescent happiness.

Some studies have quantified precisely how the social atmosphere, which pressures Korean adolescents to define themselves by their academic achievements, explains their relative unhappiness. For instance, Korean adolescents sleep an average of 7 hours and 23 minutes a night - much lower than the recommended 9 hours of sleep.
Furthermore, Korean adolescents engage in exercise for more than one hour only 3.5 days - much lower than the top rate among OECD countries (country's name here) of 4.5 days. Besides, $23 \%$ of Korean adolescents report that they have more than three hours of leisure time on weekdays, and $73 \%$ reported that they had less than three hours of leisure time on weekdays. ${ }^{1}$

Life satisfaction refers to a subjective assessment of one's quality of life or specific areas therein. ${ }^{2}$ Life satisfaction is an important sociological variable for adolescents' social adaptability and development. Previous studies have shown that adolescents' life satisfaction is associated with several variables. Reference ${ }^{3}$ reported on the factors that influence adolescent life satisfaction; ${ }^{4}$ identified self-identity, self-resilience, learning activities, and peer relationships as factors that influence adolescent life satisfaction. Furthermore, ${ }^{5,6}$ have indicated that interpersonal relationships, emotional control, and social support have mediating effects on the relationship between youth stress and life satisfaction.

\section{Corresponding Author:}

Song Hohyun, Jeonju Hosung Middle School, Department of Physical Education, Republic of Korea Email: hohyunss@nate.com

ISSN: $2231-2196$ (Print) ISSN: 0975-5241 (Online)

Received: 14.07.2020

Revised: 16.08 .2020

Accepted: 18.09 .2020

Published: 06.10 .2020 
On the other hand, a variety of studies relating to life satisfaction emphasize the relationship between adolescent health and sport participation. The numerous positive emotional experiences that can be obtained through sport participation. ${ }^{7}$ The relationship between adolescents' perception of their life satisfaction and health-related quality of life. ${ }^{8}$ The relationship between sports activity participation and engagement. ${ }^{9}$ The adolescents who were motivated to participate in sports were more engaged. ${ }^{10}$ The participation in various types of sports positively influences high school students' life satisfaction. ${ }^{11}$ Based on these findings, we can infer that participation in sports may improve adolescents' quality of life and improve their happiness.

Sports participation can be understood as a process of socialization. The term socialization of sports, which refers to an individual's acquisition of values, beliefs, and attitudes shared by a group through interaction with that group's members via participating in sports. ${ }^{12}$ Socialization agents play a very significant role in the socialization of sports. Based on the structural theory of socialization and individual internalization models, factors, which influence sport participation include (1) individual capability, character and resources; (2) influence from other key individuals, including parents, siblings, teachers, peers and role models; and (3) the validity of individually satisfying sport participation activities. ${ }^{13}$ Existing studies have reported various findings on the relationship between socialization agents and sport participation. Based on the results of existing studies, we predict that socialization agents influence adolescents' participation in sports. ${ }^{14,15,16}$

Existing studies have derived meaningful results by identifying relationships between individual variables. However, these studies are limited by the sporadic way in which these relationships are reported. Furthermore, the majority of re- search on socialization agents, sports participation, and life satisfaction has studied adults, so their findings may not apply to adolescents or other age groups. This study, therefore, fills a gap in the literature by examining the relationship between sport participation and life satisfaction in adolescents and verifying the role of socialization agents in adolescents' sport participation. It provides a significant theoretical basis for further investigating the role and importance of socialization agents vis-à-vis adolescents' sport participation.

In sum, this study highlights the structural relationships between socialization agents and adolescents' motivation to participate in sports, engagement in sports, and life satisfaction.

Its research questions are as follows.

First, how do socialization agents influence adolescents' motivation to participate in sports?

Second, what influence does adolescents' motivation to participate in sports have on their engagement in sports?

Third, how does participating in sports influence adolescents' life satisfaction?

\section{RESEARCH METHOD}

\section{Study subjects}

This study utilized the convenience sampling method to select its study participants. The study's participants were 720 Korean adolescents who regularly participate in sports activities (181 students in the pilot study, and 539 in the main). The general characteristics of the study participants are shown in Table 1.

\section{Table 1: General Characteristics of Study Participants}

\begin{tabular}{|c|c|c|c|c|c|}
\hline \multirow[t]{2}{*}{ Variable } & \multirow[t]{2}{*}{ Classification } & \multicolumn{2}{|c|}{ Pilot Study } & \multicolumn{2}{|c|}{ Main Study } \\
\hline & & $\begin{array}{l}\text { Number of Cases } \\
\text { (Number of Persons) }\end{array}$ & $\begin{array}{l}\text { Percentage } \\
(\%)\end{array}$ & $\begin{array}{c}\text { Number of } \\
\text { Cases (Number } \\
\text { of Persons) }\end{array}$ & $\begin{array}{l}\text { Percentage } \\
(\%)\end{array}$ \\
\hline \multirow[t]{2}{*}{ Gender } & Male & 101 & 55.8 & 283 & 52.5 \\
\hline & Female & 80 & 44.2 & 256 & 47.5 \\
\hline \multirow[t]{2}{*}{ School grade } & Middle school & 92 & 50.8 & 310 & 57.5 \\
\hline & High school & 89 & 49.2 & 229 & 42.5 \\
\hline \multirow{3}{*}{$\begin{array}{l}\text { The frequency with } \\
\text { which participant } \\
\text { engages in sports } \\
\text { activities }\end{array}$} & Less than once a week & 34 & 18.8 & 72 & 13.4 \\
\hline & 2-3 times a week & 88 & 48.6 & 364 & 67.5 \\
\hline & 4 or more times a week & 59 & 32.6 & 103 & 19.1 \\
\hline \multirow{3}{*}{$\begin{array}{l}\text { Duration of sport } \\
\text { participation }\end{array}$} & Less than 6 months & 41 & 22.7 & 98 & 18.2 \\
\hline & 6 months - 1 year & 78 & 43.1 & 276 & 51.2 \\
\hline & 1 year or more & 62 & 34.2 & 165 & 30.6 \\
\hline \multirow{4}{*}{$\begin{array}{l}\text { Intensity of sport } \\
\text { participation } \\
\text { (Average participa- } \\
\text { tion time per session) } \\
\text { Total }\end{array}$} & Less than 1 hour & 38 & 21.0 & 132 & 24.5 \\
\hline & 1 hour - 1 hour 30 minutes & 93 & 51.4 & 279 & 51.8 \\
\hline & More than 1 hour and 30 minutes & 50 & 27.6 & 128 & 23.7 \\
\hline & & 181 & 100 & 539 & 100 \\
\hline
\end{tabular}




\section{Verifying the study's reliability and the validity of its measurement tools}

The measurement tools used in this study are as follows. First, to measure socialization agents, this study used a scale for classifying socialization agents. ${ }^{12}$ This scale was composed of five items, each representing a different socialization agent - parents, siblings, friends or senior/junior students, teachers, and the media. Second, this study used a scale to judge adolescents' motivation to participate in sports based on the types of leisure activities classified by ${ }^{17}$ and as developed and verified for validity and reliability by. ${ }^{18}$ It consists of five sub-variables - health-orientation, self-development orientation, interpersonal orientation, home orientation, and entertainment orientation - and 20 questions that correspond to these variables. Third, we developed a questionnaire consisting of 12 questions relating to adolescents' engagement in sports based on the structure of sport engagement researched by. ${ }^{19}$ The items selected for this questionnaire were measured using a scale developed and verified for validity ${ }^{20,21}$ composed of two sub-variables: cognitive engagement and behavioural engagement. Fourth, we measured life satisfaction using questions, which had already been developed and verified for reliability by. ${ }^{22}$ Specific survey questions on life satisfaction were composed of three sub-variables - home life satisfaction, social life satisfaction, and school life satisfaction - and 15 corresponding questions. Socialization agents and adolescents' motivation to participate in sports, engagement in sports, and life satisfaction were measured using five-point Likert scales (where 5="Agree strongly" and 1="Strongly disagree"). Higher scores corresponded with a higher level of perception of the variable.

Table 2 shows the results of the reliability analysis for each variable. Specifically, The Cronbach's $\alpha$ of the scales used in this study are as follows: socialization agents, .670; participation in sports, .924; engagement in sports, .943; and life satisfaction,.927. A Cronbach's $\alpha$ of .6 or higher indicates that a scale is reliable. ${ }^{23}$ Therefore, the scales used in this study are highly reliable. Furthermore, there were no items that, once removed, led to higher Cronbach's $\alpha$ when compared to the overall Cronbach's $\alpha$, and so all items were utilized in the analysis.
Table 2: Reliability analysis for each variable

\begin{tabular}{lc} 
Variable & Cronbach's $\alpha$ \\
Socialization agents & 0.670 \\
Participation in sports & 0.924 \\
Engagement in sports & 0.943 \\
Life satisfaction & 0.927 \\
\hline
\end{tabular}

Next, we conducted a confirmatory factor analysis to verify the validity of the scales used in this study. The results are shown in Table 3. The fit of the confirmatory factor analysis was verified using an incremental fit index using NFI, IFI, and CFI, and the absolute fit index using $\chi 2 / D F$, RMSEA, GFI, and RMR. ${ }^{24}$ argued that confirmatory factor analyses should consider a variety of fit indices but focus on CFI and RMSEA as key evidence for decisions. We found the confirmatory factor analysis of this study to be acceptable.

\section{Table 3: Confirmatory Factor Analysis Goodness of Fit - Hypothesis Model

X2/DF RMR GFI NFI IF CFI RMSEA \\ $\begin{array}{llllllllll}\text { Hypothesis } & 2.174 & 0.048 & 0.885 & 0.881 & 0.932 & 0.931 & 0.081\end{array}$ model}

Next, this study verified the validity of the model based on the results of the confirmatory factor analysis. The results are shown in Table 4 . The convergent validity of the model can be verified by measuring its standardized regression coefficient, average variance extracted, and construct reliability ${ }^{25}$. The confirmatory factor analysis indicated that the standardized regression coefficients of all variables ranged between .483 and .927 , and the significance (CR values) were higher than 1.965 . Furthermore, the construct reliability was between .925 and .994 , and the average of the variance extracted was between .714 and .938 . Each of these three conditions was met, thus verifying the convergent validity of the model.

Table 4: Confirmatory Factor Analysis Results

\begin{tabular}{|c|c|c|c|c|c|c|c|c|c|}
\hline & & & $\begin{array}{l}\text { Unstandardized } \\
\text { coefficient }\end{array}$ & S.E. & C.R. & $\mathbf{p}$ & $\begin{array}{l}\text { Standardized } \\
\text { Coefficient }\end{array}$ & $\begin{array}{l}\text { Construct } \\
\text { Reliability }\end{array}$ & $\begin{array}{c}\text { Average } \\
\text { Variance } \\
\text { extracted }\end{array}$ \\
\hline \multirow{5}{*}{$\begin{array}{l}\text { Sociali- } \\
\text { zation } \\
\text { agents }\end{array}$} & $\rightarrow$ & Media & 1 & & & - & 0.483 & \multirow[t]{5}{*}{0.925} & \multirow[t]{5}{*}{0.714} \\
\hline & $\rightarrow$ & Teacher & 1.043 & 0.223 & 4.673 & $0.000^{* * *}$ & 0.528 & & \\
\hline & $\rightarrow$ & Peers & 1.025 & 0.218 & 4.693 & $0.000^{* * *}$ & 0.532 & & \\
\hline & $\rightarrow$ & Siblings & 1.161 & 0.244 & 4.766 & $0.000^{* * *}$ & 0.547 & & \\
\hline & $\rightarrow$ & Parents & 1.085 & 0.215 & 5.037 & $0.000^{* * *}$ & 0.612 & & \\
\hline
\end{tabular}


Table 4: (Continued)

\begin{tabular}{|c|c|c|c|c|c|c|c|c|c|}
\hline & & & $\begin{array}{l}\text { Unstandardized } \\
\text { coefficient }\end{array}$ & S.E. & C.R. & $\mathbf{p}$ & $\begin{array}{c}\text { Standardized } \\
\text { Coefficient }\end{array}$ & $\begin{array}{l}\text { Construct } \\
\text { Reliability }\end{array}$ & $\begin{array}{c}\text { Average } \\
\text { Variance } \\
\text { extracted }\end{array}$ \\
\hline \multirow{5}{*}{$\begin{array}{l}\text { Motiva- } \\
\text { tion to } \\
\text { Par- } \\
\text { ticipate in } \\
\text { Leisure } \\
\text { Sports }\end{array}$} & $\rightarrow$ & Social & 1 & & & - & 0.704 & 0.987 & 0.939 \\
\hline & $\rightarrow$ & Self & 1.121 & 0.109 & 10.316 & $0.000^{* * * *}$ & 0.831 & & \\
\hline & $\rightarrow$ & Home & 1.073 & 0.111 & 9.657 & $0.000^{* * *}$ & 0.774 & & \\
\hline & & Health & 0.645 & 0.084 & 7.67 & $0.000^{* * *}$ & 0.609 & & \\
\hline & $\rightarrow$ & Leisure & 0.974 & 0.094 & 10.325 & $0.000^{* * *}$ & 0.832 & & \\
\hline \multirow[t]{2}{*}{$\begin{array}{l}\text { Leisure } \\
\text { engage- } \\
\text { ment }\end{array}$} & $\rightarrow$ & $\begin{array}{l}\text { Behav- } \\
\text { ioural } \\
\text { engage- } \\
\text { ment }\end{array}$ & 1 & & & - & 0.862 & 0.977 & 0.956 \\
\hline & $\rightarrow$ & $\begin{array}{l}\text { Cogni- } \\
\text { tive } \\
\text { engage- } \\
\text { ment }\end{array}$ & 0.995 & 0.072 & 13.905 & $0.000^{* * * *}$ & 0.905 & & \\
\hline \multirow[t]{3}{*}{$\begin{array}{l}\text { Life } \\
\text { Satisfac- } \\
\text { tion }\end{array}$} & $\rightarrow$ & $\begin{array}{l}\text { School } \\
\text { satisfac- } \\
\text { tion }\end{array}$ & 1 & & & - & 0.927 & 0.994 & 0.983 \\
\hline & $\rightarrow$ & $\begin{array}{l}\text { Social } \\
\text { satisfac- } \\
\text { tion }\end{array}$ & 1.055 & 0.058 & 18.153 & $0.000^{* * * *}$ & 0.897 & & \\
\hline & $\rightarrow$ & $\begin{array}{l}\text { Home } \\
\text { satisfac- } \\
\text { tion }\end{array}$ & 0.928 & 0.058 & 16.059 & $0.000^{* * *}$ & 0.842 & & \\
\hline
\end{tabular}

${ }^{* * *} p<.001$

Next, this study compared the correlation between construct concepts and the average variance extracted to verify the study's discriminant validity. The results are shown in Table 5 . We verified the discriminant validity between variables by selecting the two most-correlated variables and comparing them with the average variance extracted. The square of the correlation coefficient of the highest-correlation (between "sports participation motivation" and "sport activity engagement") is .445; lower than sports participation motivation (.939) and sport activity engagement (.956). These results confirm the discriminant validity of the variables in this study.

Table 5: Verification of Discriminant Validity

\begin{tabular}{lccccc} 
Variable Name & \multicolumn{3}{c}{ Correlation between Construct Concepts } & $\begin{array}{c}\text { Average Variance } \\
\text { Extracted }\end{array}$ \\
Socialization agents & 1 & 2 & 3 & 4 & 0.714 \\
Sport participation motivation & 1 & - & - & - & 0.939 \\
Sport activity engagement & $0.526^{*+*}$ & 1 & - & - & 0.956 \\
Life satisfaction & $0.523^{*+*}$ & $0.667^{+*+*}$ & 1 & - & 0.983 \\
\hline
\end{tabular}

${ }^{* * *} p<.001$

\section{DATA COLLECTION AND ANALYSIS METHODOLOGY}

We conducted a pilot study with 200 Korean adolescents in December 2019. After excluding 19 responses because they had missing answers and/or insincere responses, we used a total of 181 surveys in the research. The survey for the main study was distributed to 550 Korean adolescents in February 2020. As with the pilot study, 11 cases were excluded. This left us with a total of 539 surveys for the main study. The 
data acquired from the pilot study and the main study were analyzed using SPSS 18.0 and AMOS 18.0. Our specific method of analysis was as follows. First, we conducted a frequency analysis to confirm the general characteristics of the participants. Second, we used the Cronbach's $\alpha$ coefficient to analyze the reliability of the study tools. Third, we used confirmatory factor analysis to verify the study tools' convergent and discriminant validity. Fourth, we used a descriptive statistics analysis to confirm the study participants' perceptions of each variable. Fifth, we verified the hypothesis model's goodness of fit to verify the relationships between each variable and conducted a path analysis.

\section{RESULTS}

\section{Descriptive statistics analysis}

The results of our analysis of each variable (socialization agents, sports participation motivation, sports activity en- gagement, and life satisfaction)'s score and descriptive statistics of the sub-variables (mean, standard deviation, skewness, and kurtosis) are shown in Table 6. The mean is distributed between 2.92 and 4.15, with a standard deviation distribution between .60 and 1.29. Next, the absolute value of skew is distributed between 0.10 and 1.01 , and the absolute value of kurtosis is distributed between .00 and 12.03. The criteria for a violated univariate normality, which is skewness $< \pm 3.0,{ }^{26}$ and kurtosis $< \pm 10.0,{ }^{27}$ satisfy the conditions for a normal distribution. Considering the above, the sub-variable "health orientation" had kurtosis values of 12.03, which exceeded the requirements. As such, it was deleted before proceeding with the study. All other values satisfied the criteria.

\section{Table 6: Descriptive Statistics Analysis}

\begin{tabular}{llcccc} 
Variable & & Mean & Standard Deviation & Skew & Kurtosis \\
Socialization agents & Parents & 3.63 & 1.05 & -0.53 & -0.14 \\
& Siblings & 2.92 & 1.29 & -0.10 & -1.03 \\
& Peers & 3.77 & 1.12 & -0.77 & 0.00 \\
& Teacher & 3.19 & 1.16 & -0.27 & -0.56 \\
& Media & 3.39 & 1.24 & -0.45 & -0.63 \\
Total & & 3.38 & 0.72 & -0.24 & 0.23 \\
Sports participation motivation & Leisure & 30.91 & 0.80 & -0.69 & 0.31 \\
& Health & 30.70 & 0.78 & 1.01 & 12.03 \\
& Home & 30.15 & 0.92 & -0.13 & -0.28 \\
& Self & 30.56 & 0.91 & -0.32 & -0.31 \\
Total & Social & 30.22 & 0.94 & -0.11 & -0.27 \\
Sport activity engagement & & 3.51 & 0.69 & -.22 & 0.28 \\
& Cognitive engagement & 30.89 & 0.84 & -0.51 & 0.13 \\
Total & Behavioral engagement & 30.43 & 0.95 & -0.22 & -0.32 \\
Life satisfaction & & 3.74 & 0.83 & -0.39 & 0.02 \\
& Home satisfaction & 40.13 & 0.67 & -0.86 & 0.74 \\
& Social satisfaction & 40.03 & 0.70 & -0.32 & -0.58 \\
Total & School satisfaction & 40.15 & 0.62 & -0.39 & -0.59 \\
\hline & & 4.10 & 0.60 & -0.38 & -0.52 \\
\hline
\end{tabular}

\section{Path analysis}

This studynalysisonntmentationsis. $0,{ }^{27}$ satisfy the conditionalization agents, sports participation motivation, sports activity engagement, and life satisfaction) and 14 observed variables. Before the path analysis, we verified the goodness of fit of this study's initial, proposed model and a modified model. The results are shown in Table 7 . The results indicated that the overall fit was poor, and so we covariance the error terms of the measurement variables with high modified index values. The modified measurement variables with high Modi 
Table 7: The Goodness of Fit for Both the Hypothesis Model and Modified Model

\begin{tabular}{lcccccccc} 
Model & X2/DF & RMR & GFI & NFI & IFI & TLI & CFI & RMSEA \\
Proposed model & 6.229 & 0.061 & 0.887 & 0.878 & 0.896 & 0.871 & 0.895 & 0.099 \\
Modified model & 4.887 & 0.055 & 0.914 & 0.908 & 0.926 & 0.904 & 0.925 & 0.085 \\
\hline
\end{tabular}

Next, we conducted a path analysis for the modified model. The results are shown in Table 8. First, we analyzed socialization agents' influence on adolescents' motivation to participate in sports; the path coefficient was .789 $(t=8.413)$ and had a positive influence, which was under the significance level (H1). Second, we analyzed adolescents' motivation to participate in sports on their engagement; the path coefficient was $.930(t=21.638)$ and had a positive influence, which was under the significance level (H2). Third, we analyzed adolescents' engagement in sports' influence on their life satisfaction; the path coefficient was $376(t=10.685)$ and had a positive influence, which was under the significance level (H3).

\section{Table 8: Model Parameter Estimation Results}

\begin{tabular}{|c|c|c|c|c|c|c|c|}
\hline Path & Path & & & Estimate & S.E. & C.R. & $\mathbf{p}$ \\
\hline $\mathrm{H}_{1}$ & Socialization agents & $\rightarrow$ & $\begin{array}{l}\text { Sports participation } \\
\text { motivation }\end{array}$ & 0.789 & 0.094 & 8.413 & $0.000^{*+4 x}$ \\
\hline $\mathrm{H}_{2}$ & $\begin{array}{l}\text { Sports participation } \\
\text { motivation }\end{array}$ & $\rightarrow$ & $\begin{array}{l}\text { Sport activity engage- } \\
\text { ment }\end{array}$ & 0.930 & 0.043 & 21.638 & $0.000^{* * *}$ \\
\hline $\mathrm{H}_{3}$ & $\begin{array}{l}\text { Sport activity engage- } \\
\text { ment }\end{array}$ & $\rightarrow$ & Life satisfaction & 0.376 & 0.035 & 10.685 & $0.000^{*+* x}$ \\
\hline
\end{tabular}

${ }^{* * *} p<0.001$

\section{DISCUSSION}

This study examined the relationship between socialization agents and adolescents' sport participation and life satisfaction to complement and develop the results of existing research. Its three main findings are discussed below.

First, this study analyzed the relationship between socialization agents and adolescents' motivation to participate in sports. The results indicated that socialization agents had a positive influence on adolescents' motivation to participate in sports. Previously, ${ }^{16,28}$ have reported on the variables that influence adolescents' participation in sports and mentioned the importance of socialization agents. Furthermore, ${ }^{14}$ reported that socialization agents influence adolescents' participation in sports. ${ }^{29,30}$ Therefore, this first result of this study is supported by the literature. These results can be partially explained by common sense: humans are influenced by those around them to adapt to groups and situations. ${ }^{31}$ argued that athletes decide to participate and concentrate on their chosen sport based on a self-assessment of whether they have the potential to succeed in that particular sport and based on the individual relationships they have formed with people through that particular sport. As such, socialization agents play a critical role in adolescents' motivation and decision to participate in sports. Therefore, sports and educational institutions should devise methods to actively spur various socialization agents to encourage adolescents to participate in sports.

Second, this study analyzed the relationship between adolescents' motivation to participate in sports and their en- gagement in sports. It found that adolescents' motivation to participate in sports positively influenced their engagement in sports. Several studies have reported that adolescents' motivation to participate in sports has a positive influence on their engagement in sport across multiple sports. Thus, this second finding of this study is also supported by the literature $^{32-35}$ These results can be interpreted to mean that adolescents participate in sports for various reasons - e.g., the enjoyment of engaging in new things, the potential for individual achievement, the experience of sensory enjoyment and physical activity, and enjoying sports themselves. Which in turn leads them to higher levels of focus and engagement.

Third, this study analyzed the relationship between adolescents' engagement in sports and their life satisfaction. It found that adolescents' engagement in sports positively influenced their life satisfaction. Other studies have found that students participating in sports clubs report high levels of life satisfaction - thus, this third finding of our study is supported by the literature. ${ }^{36,37}$ These results can be interpreted as meaning that adolescents can effectively manage stress from university entrance exams and other stresses related to their future by engaging in sports activities during their leisure time. Therefore, we suggest that schools and other institutions provide the physical environment and social conditions required to encourage and help adolescents select and participate in sports. ${ }^{38}$

This study examined the relationships of variables of this study comprehensively and found that socialization agents influenced adolescents participating in sports, and active sports participation could raise life satisfaction. Particu- 
larly, given the nature of youth who are heavily influenced by those around them, socialization agents can be seen as important variables that motivate the adolescents to participate in sports. ${ }^{39,40}$ For adolescents who are sensitive to social trends and have clear responses toward changes of the times, sports activities will help them through physical, mental and social development, and ultimately to become holistic human beings that are needed in the society. ${ }^{41,42}$ Furthermore, this study is expected to help in understanding the comprehensive relationship between various predictor variables to raise the life satisfaction of adolescents who are stressed from their academically focused lifestyles.

\section{CONCLUSIONS AND RECOMMENDATIONS}

This study confirmed the structural relationship between socialization agents and adolescents' participation in sports and life satisfaction. It found that socialization agents positively influenced adolescents' motivation to participate in sports, which in turn positively influenced their engagement in sports, which in turn positively influenced their life satisfaction.

This study considered the functional aspects of socialization agents and how they can contribute to the healthy development and life satisfaction of adolescents. While this study produced some meaningful results, it has its limitations. Future studies should extend this study's findings and methods in the following three ways. First, because the study's participants were all adolescents living in a certain part of South Korea, it is difficult to generalize the results of the study. Second, this study focused on a small set of loosely defined socialization agents; future studies should study a broad variety of agents and factors that might influence adolescents' motivation and decision to participate in sports. Third, we performed a cross-sectional study on the abovementioned relationships; however, because participation in sport and life satisfaction can change continuously, depending on circumstances, future researchers should plan and execute a longitudinal study to better examine the relationships between these and other variables.

\section{REFERENCES}

1. National Youth Policy Institute. Korean Children and Youth Panel Survey X: Data Analysis Report - Types of Youth Life Hours. Research Report of National Youth Policy Institute. 2016.

2. Diener E, Suh EM, Lucas RE, Smith HL. Subjective well-being: Three decades of progress. Psychological bulletin. 1999 Mar;125(2):276.

3. Seo JA, Kim HW. Changes in young youths' satisfaction with their life and influence factors: Centering on family structures and functions. Seoul: Research Report of National Youth Policy Institute, 1-86; 2013.
4. Kim, D. S., Jeong, S. I. An analysis of the structural relationship between variables affecting adolescent life satisfaction and differences according to the dating experience. Studies on Korean Youth, 2017;28(3):29-56.

5. Park, B. S. Multiple Mediating Effects of Interpersonal Relationship and Community Support on the Relation of Emotional Problems and Life Satisfaction among Adolescents.Journal of Adolescent Welfare, 2015;17(4):25-47.

6. Moon, D. W., Shin, H. J., \& Lee, J. M. The Mediating Effects of AdolescentsingEffe Regulation and Family Intimacy on the Relationships Between Stress and Life Satisfaction. J. Fut. Oriented Youth Soci.. 2017;14(2):69-92.

7. Jackson SA. Joy, fun, and flow state in sport. Emotions in sport. 2000 Jan 1:135-55.

8. Zullig KJ, Valois RF, Huebner ES, Drane JW. Associations among family structure, demographics, and adolescent perceived life satisfaction. Journal of Child and Family studies. 2005 Jun 1;14(2):195-206.

9. Nam, J. H., Nam, S. K. Effects of Participation in Adolescent Physical Activities with the Flow and Self-achievement. The Korean Journal of Sport. 2017;15(3):211-219.

10. Lee, S. M., \& Lee, C. H. The relationship between leisure sports participation motive, sports participation, leisure satisfaction, and leisure continuance in the adolescent: Structural equation modelling. Journal of Learner-Centered Curriculum and Instruction. 2017;17(23):779-798.

11. Kim, H. J., Lee, S. M., Lee, C. H. The Structural Relationship between the Motivation to Participate in Leisure Sports, Leisure Flow, and Life Satisfaction of High School Student. Journal of Learner-Centered Curriculum and Instruction. 2020;20(8):101120 .

12. Kenyon GS, McPherson BD. Becoming involved in physical activity and sport: A process of socialization. Physical activity: Human growth and development. 1973:303-32.

13. Corbett D. Ethics and moral behaviour in sport: A human rights issue. HOW YOU PLAY THE GAME. 1999 Sep 1:165.

14. Lee, J. The Causal Relationship Model Among Socializing Agents of Sports for All, Self-Identity and Participation in Sports for All of the Adolescents. Korean Society of Sport Policy. 2015;5:127-138.

15. Jeong, S. H., Kim, H. Y. Effect on the youth's participating in leisure sports caused by the personnel of Sports Socialization. Korean Society of Leisure Sport Fishing. 2009;1:49-59.

16. Fredricks JA, Eccles JS. Parental influences on youth involvement in sports. 2014.

17. Dumazedier, J. Sociology of leisure. Elsevier Scientific Publ. Co. 1974.

18. Lee, C. H. A Study on the Motives and Satisfaction of Sports Activities in Urban Married Women. (Docter's thesis, Korea University, Seoul, Korea). 1995.

19. Carpenter PJ, Scanlan TK, Simons JP, Lobel M. A test of the sport commitment model using structural equation modelling. Journal of Sport and Exercise Psychology. 1993 Jun 1;15(2):119-33.

20. Jung YG. The influence of sport participation motivation, arousal seeking and affects the behaviour of sport commitment. Unpublished doctoral dissertation). Pusan National University, South Korea. 1997.

21. Jung YG. Validity verification of sport commitment behaviour scale. Korean Society of Sport Psychology. 2004;15(1):1-21.

22. Huebner ES. Initial development of the student's life satisfaction scale. School Psychology International. 1991 Aug;12(3):231-40.

23. Song, J. J. Understanding and Application of thesis Statistics. Gyeonggi: Hakjisa press. 2019. 
24. Hong S. The criteria for selecting appropriate fit indices in structural equation modelling and their rationales. Korean Journal of Clinical Psychology. 2000;19(1):161-77.

25. Bea, B. R. Amos 24 Structural Equation Modeling. Seoul: Chungram Press. 2011.

26. West SG, Finch JF, Curran PJ. Structural equation models with nonnormal variables: Problems and remedies. 1995.

27. Kline RB. Principles and practice of structural equation modelling. Guilford publications; 2015 Nov 3.

28. Brustad RJ. Integrating Socialization Influences into the Study of Children's Motivation in Sport. Journal of Sport and Exercise Psychology. 1992 Mar 1;14(1):59-77.

29. Han LS. The Influence of Parental Encouragement on Youth Sport Involvement.International Conference on Sports Science. 1998 Jun:193-202.

30. Song, M. S., Ihm, S. Y. The Effect of Members of Society on Elementary School Student's Sports Participation. Journal of Exercise and Sport Science. 2000;6:85-102.

31. Stevenson CL. Seeking identities: Towards an understanding of the athletic careers of masters swimmers. International Review for the Sociology of Sport. 2002 Jun;37(2):131-46.

32. Kim, W. H., Yi, B. The structural relationship between Passion, Commitment and Adherence in amateur golfers. The Korean Society of Sports Science. 2015;24(1):379-388.

33. Bong, S. Y., Jun, S. H. The Effects of sources of Enjoyment and the Level of Participation on the sport Commitment for Basketball Club Members. Journal of Korean Physical Education Association for Girls and Women. 2010;24(4):117-130.

34. Jung DC. Structural equation modelling analysis of participation motivation, sport commitment, participation satisfaction, and continuous participation intention in swimming partici- pants. Unpublished doctoral dissertation, Kyungnam University. 2011;13(4):31-40.

35. Lee JH, Kim JW, Park YB. Relation among participation motive, sports immersion and participation satisfaction of skin scumarba's participants. Journal of leisure and recreation studies. 2010;34(3):115-26.

36. Kwon, Y. T., Shin, J. H. The Effect of Futsal Attendance Attributes on Participatory Attitude and Re-Participation Behavior. J. Kor. Data Anal. Soci. 2017;19(5):2709-20.

37. Lee CH. Participation in Sports Activities and School Life Satisfaction in Adolescent.Journal of the School Sports Research Institute. 2012;19(1):381-404.

38. Lee, S. M., Song, J. H., Song, H. H. The Relationship between Participation in Sports and Life Satisfaction in Adolescent. International Journal of Interactive Storytelling. 2020;4(1):25-32.

39. Ahn, B. W., Lee, W. Y., Cho, W. H. Q Methodology of Gender Identity for Sports Participants.International Journal of IT-based Social Welfare Promotion and Management. 2016;3(1):201-204.

40. Jeong, G. C., Kim, J. H. Shim, H. C. A Study on the Feasibility Study for Local Government Investment Projects- Focusing on the development of local sports complex. International Journal of Social Welfare Promotion and Management. 2019;6(2):55-62.

41. Sin, J.G., Park, J.L., Choi, J. H. The Relationship between Participation in After-school Sports Club, Academic Emotional Regulation and Self-Efficacy of Middle School Students. International Journal of Child Warfare Promotion and Management. 2018;2(2):7-12.

42. Jang, H.A., Choi, J. H., Park, J. L. The Effect of Middle School Students` Participation in Saturday Sports on Physical Self-Efficacy and Self-Directed Learning Ability. International Journal of Child Warfare Promotion and Management. 2018;2(2):13-18. 